\title{
In vivo performance of different scaffolds for dental pulp stem cells induced for odontogenic differentiation
}

\section{Cigdem ATALAYIN ${ }^{(a)}$ \\ Huseyin TEZEL(a) \\ Taner DAGCI (b) \\ Nefise Ulku KARABAY \\ YAVASOGLU(c) \\ Gulperi OKTEM(d) \\ Timur KOSE(e)}

\footnotetext{
(a)Ege University, School of Dentistry, Department of Restorative Dentistry, Izmir, Turkey.

(b) Ege University, School of Medicine, Department of Physiology, Izmir, Turkey.

(c)Ege University, Faculty of Science, Department of Biology, Izmir, Turkey.

(d) Ege University, School of Medicine, Department of Histology and Embryology, Izmir, Turkey.

(e)Ege University, School of Medicine, Department of Biostatistics and Medical Informatics, Izmir, Turkey.
}

Declaration of Interests: The authors certify that they have no commercial or associative interest that represents a conflict of interest in connection with the manuscript.

\section{Corresponding Author: \\ Cigdem Atalayin \\ E-mail:dtcatalayin@gmail.com}

DOI: 10.1590/1807-3107BOR-2016.vol30.0120

Submitted: May 5, 2016

Accepted for publication: Aug 16, 2016

Last revision: Sep 1, 2016

\begin{abstract}
This study was designed to determine the in vivo performance of three different materials as scaffolds for dental pulp stem cells (DPSC) undergoing induced odontogenic differentiation. An odontogenic medium modified by the addition of recombinant human bone morphogenetic protein 2 was used in the experimental groups to induce differentiation. Mesenchymal stem cell medium was used in the control groups. DPSC were transplanted onto the backs of mice via three scaffolds: copolymer of L-lactide and DL-lactide (PLDL), copolymer of DL-lactide (PDL) and hydroxyapatite tricalcium phosphate (HA/TCP). The expression levels of dentin sialo-phosphoprotein (DSPP), dentin matrix protein-1 (DMP1), enamelysin/matrix metalloproteinase 20 (MMP20) and phosphate-regulating gene with homologies to endopeptidases on X chromosome (PHEX) were analysed using RT-PCR. The expressions in the experimental groups were compared to those in the control groups. The transcript expressions at 6 and 12 weeks were significantly different for all scaffolds ( $\mathrm{p}<0.05)$, except for the expression of DSPP in the PLDL group with regard to the time variable. Although there was a decrease in the expression of enamelysin/MMP20 in PLDL and HA/TCP at 12 weeks, all other expressions increased and reached their highest level at 12 weeks. The highest DSPP expression was in the PDL group $(p<0.05)$. The highest expression of DMP1 was detected in the HA/TCP group ( $p$ <.05). The highest expression of PHEX was in the PLDL group $(p<0.05)$. Consequently, PLDL and PDL seemed to be promising scaffold candidates for odontogenic regeneration at least as HA-TCP, when they were applied with the DPSC induced for odontogenic differentiation.
\end{abstract}

Keywords: Dentistry; Regeneration; Dental Pulp.

\section{Introduction}

The current dental treatments are unable to restore full biological function, including the mechanical properties of the lost or damaged tissue. The 'regenerative dentistry' concept of biological tooth repair appears to be a promising alternative for the future of dentistry. ${ }^{1}$ Although different stem cells, morphogens and scaffolds can be combined to simulate natural odontogenic regeneration, it is crucial to determine which options most closely replicate the characteristics of human dental tissues.

Dental pulp stem cells (DPSC) seem to be the most appropriate cell group for the regenerative approach. ${ }^{2}$ They have a higher odontogenic 
differentiation capacity compared to other cell groups due to their content of specific progenitor cells. ${ }^{3}$ Odontogenic differentiation of DPSC can be induced using various factors; for example, dexamethasone has been reported as the main inductive factor in previous DPSC studies. ${ }^{4,5,6}$ Bone morphogenetic proteins (BMP), known as active components of odontogenic differentiation and tooth development, have been used as a growth factor in an appropriate medium., ${ }^{7,8}$ This combination of inductive factors has been suggested as being more effective in enhancing differentiation. ${ }^{4,9,10}$ Hence, it may be useful to investigate different medium modifications to create effective combinations of factors for inducing odontogenic differentiation.

Scaffolds imitate the conditions in the tissue. ${ }^{11}$ The properties of a scaffold material are important. It must simulate the biological matrix and provide the desired tissue formation. ${ }^{12}$ Many types of natural and synthetic materials have been tested as scaffolds in regenerative dentistry; nevertheless, there is still a need for new materials and designs. Both ceramics and synthetic polymers can provide optimal scaffold structures. ${ }^{13}$ Hydroxyapatite tricalcium phosphate (HA-TCP) has been reported to be an appropriate scaffold material for DPSC and odontogenic regeneration. ${ }^{6,14,15}$ Synthetic polymers are increasingly in demand as scaffold materials due to their properties of biocompatibility, biodegradability and the incorporation of bioactive molecules. ${ }^{13}$ Copolymers, including a poly-L/DL lactide that is used in medical applications, may also be an option to consider when devising new scaffold materials.

The aim of this study was to determine the in vivo performance of different scaffold materials, i.e., a copolymer of L-lactide and DL-lactide (PLDL), a copolymer of DL-lactide (PDL) and hydroxyapatite tricalcium phosphate (HA/TCP) for DPSC induced for odontogenic differentiation by medium modification.

\section{Methodology}

\section{Cell culture}

Human impacted third molar teeth $(\mathrm{n}=15)$ that had been surgically extracted were used as the cell source. The study protocol was approved by the Human Ethical Committee of Ege University
(Research no. 11-5.1/8), and informed consent was obtained from the patients. A previously reported isolation and culture method was used. 5,13,14

The cells were analysed with flow cytometry using a FACSCalibur (BD Biosciences, CA, USA), and the data were analysed using the Cell Quest software (BD Biosciences, CA, USA) to determine the phenotypic characteristics. Stem cells that were negative for CD34 (hematopoietic progenitor cell antigen; APC) and CD45 (leucocyte common antigen/cell marker of hematopoietic origin; APC-H) but positive for CD73 (NTES'-nucleotidase; PE) and CD90 (thymus cell antigen/Thy-1/Thy-1.1; FITC) were selected for this study. The rate of mesenchymal clusters of differentiation (CD73+CD90) was $98.3 \%$.

In the control (-) groups, a mesenchymal stem cell medium ${ }^{13}$ containing an alpha modification of Eagle's medium (Gibco Invitrogen, Grand Island, USA) supplemented with 15\% fetal bovine serum (FBS) (Gibco Invitrogen, Grand Island, USA), $0.1 \mathrm{mM}$ L-ascorbic acid phosphate (Sigma-Aldrich, St. Louis, MO, USA), 2 mM L-glutamine (Sigma-Aldrich, St. Louis, MO, USA) and 100 units/ml penicillin/streptomycin (Gibco Invitrogen, Grand Island, USA) was used during the culture period. In the experimental $(+)$ groups, the medium was modified by adding $0.01 \mu \mathrm{M}$ dexamethasone sodium phosphate, $1.8 \mathrm{mM}$ monopotassium phosphate $\left(\mathrm{KH}_{2} \mathrm{PO}_{4}\right)$ and $50 \mathrm{ng} / \mathrm{ml}$ recombinant human bone morphogenetic protein 2 (rhBMP2) (ProSpec-Tany TechnoGene Ltd., Israel) to induce odontogenic differentiation. ${ }^{8,13}$ The cells were cultured at $37^{\circ} \mathrm{C}$ in $5 \% \mathrm{CO}_{2}$ and the medium was changed every two days.

\section{Preparation of scaffolds}

Three different scaffold materials $(40 \mathrm{mg}$ ) were used as follows;

a. PLDL in a 80/20 molar ratio with an inherent viscosity midpoint of $5.8 \mathrm{dl} / \mathrm{g}$ (Purasorb PLDL, Purac, Holland)

b. PDL with an inherent viscosity midpoint of $2.0 \mathrm{dl} / \mathrm{g}$. (Purasorb PDL, Purac, Holland)

c. HA-TCP ceramic powder (Zimmer, Warsaw, Indiana, USA)

The polymer scaffolds, PLDL and PDL, were dissolved in dioxane before being mixed with the 
cells. The cell suspensions, containing $\sim 1 \times 10^{6}$ DPSC cultured to the third passage, were mixed with the appropriate scaffold material, and transplantation was performed as described below.

\section{Transplantation}

All transplantation procedures were performed under sterile conditions and in accordance with the guidelines approved by the Animal Ethical Committee of Ege University (Research no. 2010-21). Fifty mg/kg Ketamine $\mathrm{HCl}$ (Alfamine ${ }^{\circledR}$ ), $5 \mathrm{mg} / \mathrm{kg}$ Xylazine $\mathrm{HCl}$ (Alfazyne ${ }^{\circledR}$ ) and $1 \mathrm{mg} / \mathrm{kg}$ acepromazine maleate were intraperitoneally administered to each of the immunocompromised mice. The dorsal surface of each mouse was shaved and cleaned, and one midsagittal incision was made. A mixture of cell suspension and scaffold ( $\mathrm{n}=3$ for each group) was then placed into a pocket that was prepared subcutaneously to the dorsal surface of each immunocompromised mouse. The pockets and incision lines were closed. The animals were euthanized with $100 \mathrm{mg} / \mathrm{kg}$ thiopental sodium at 6 or at 12 weeks; the samples were removed 6 or 12 weeks, respectively, after the transplantation, and the structure of the formed tissues was investigated using Real Time-Polymerase Chain Reaction (RT-PCR).

\section{Gene expression analysis}

The expressions of the following human enamel and dentin specific transcripts in the formed tissues were evaluated using RT-PCR: dentin sialo-phosphoprotein (DSPP), dentin matrix protein-1 (DMP1), enamelysin/matrix metalloproteinase 20 (MMP20) and the phosphate-regulating gene with homologies to endopeptidases on the X chromosome (PHEX). The total RNAs of the tissue were isolated at 6 and 12 weeks using the TriPure Isolation Reagent (Roche, Cat No 11667157 001) following the manufacturer's instructions. First-strand cDNAs were synthesized with a Transcriptor First Strand cDNA Synthesis Kit (Roche, Cat No 04379012 001) using the total RNA. Specific primers were purchased as follows;

DSPP forward: 5'AACATCACAGCAAATGGCATC DSPP reverse: 5'CTTCCAGCTACTTGAGGTCCA DMP1 forward:5'AGACAGTGCCCAAGATACCACC DMP1 reverse: 5'ATTCCCTCATCGTCCAACTCG MMP20forward:5’ACAAGCAGCCTCTAACTGGATC
MMP20reverse:5'GATTTCGCATAAAGTTGCCCAT PHEX forward: 5'AACTTTGCTGCCTCAATGGGA PHEX reverse: 5' GTCAATAAAGGCCCAGCGAAC $\beta$-actin forward: 5' AGCCTCGCCTTTGCCGA $\beta$-actin reverse: $5^{\prime}$ CTGGTGCCTGGGGCG

A total of $0.3 \mathrm{ml}$ of each primer $(0.5 \mathrm{mM})$ was mixed with $10.5 \mathrm{ml}$ of LightCycler FastStart DNA Master SYBR Green I (Roche, Cat no: 03003230 001) for a final volume of $18 \mathrm{ml}$. The standard cycling conditions were $95^{\circ} \mathrm{C}$ for $10 \mathrm{~min}$, followed by 40 cycles of $95^{\circ} \mathrm{C}$ for $15 \mathrm{~s}, 62^{\circ} \mathrm{C}$ for $8 \mathrm{~s}$ and $72^{\circ} \mathrm{C}$ for $13 \mathrm{~s}$. The comparative Ct method (2- ${ }^{\Delta \Delta \mathrm{Ct}}$ method) was used to analyse the data. ${ }^{16}$ The expression of genes was normalized using the glucose $\beta$-actin gene as a control housekeeping gene. The relative changes in the expression levels of the analysed genes in the experimental group were compared to those in the control group. The details of the analysis were as follows:

Ct: Threshold cycle, HKG: Housekeeping gene ( $\beta$-actin), GOI: Experimental gene

$\Delta \mathrm{Ct}$ (Control): $\mathrm{Ct}(\mathrm{GOI})-\mathrm{Ct}(\mathrm{HKG})$

$\Delta \mathrm{Ct}$ (Experimental): $\mathrm{Ct}(\mathrm{GOI})-\mathrm{Ct}(\mathrm{HKG})$

$\Delta \Delta \mathrm{Ct}: \Delta \mathrm{Ct}$ (Experimental) $-\Delta \mathrm{Ct}$ (Control)

Fold change: $2^{-\Delta \Delta C t}$

IBMSPSS (Version 20.0) was used for the statistical analysis. The variables were summarized by means of mean \pm standard deviation. First, the scaffold type (repeated factor) and time effect (independent factor) were analysed using a repeated measures ANOVA. Because the scaffold $x$ time interaction was found to be significant, the results at 6 and 12 weeks were measured and tested separately based on the scaffold type (PLDL $x$ PDL $x$ HA-TCP) by means of repeated measures ANOVA followed by a Bonferroni correction. Finally, $6^{\text {th }}$ week $\times 12^{\text {th }}$ week comparisons for each scaffold were analysed via a two independent samples t-test. All hypothesis tests were performed at the $\alpha=0.05$ significance level.

\section{Results}

The fold change rates were obtained for each time point. The expression of human enamel-dentin specific transcripts in the experimental $(+)$ groups compared to the control (-) groups was determined. There were differences in transcript expressions with regard to both the groups and the time variables $(p<0.05)$. 
The differences between the groups are presented in Table. The fold changes in gene expression are shown in Figure. The transcript expressions at 6 and 12 weeks were significantly different for all scaffold materials ( $p<0.05)$, except for a lack of difference in the expression of DSPP in the PLDL group with regard to the time variable $(p>0.05)$. Although there was a decrease in the expression of enamelysin/MMP20 in PLDL and HA/TCP at 12 weeks, all other expressions were observed to have increased and reached their highest level at 12 weeks.

There was no significant difference between the PLDL, PDL and HA/TCP groups for DSPP expression at 6 weeks $(\mathrm{p}>0.05)$. The highest $D S P P$ expression

Table. The fold change rates of DSPP, DMP1, MMP20 and PHEX (mean \pm std). The superscripts indicate statistically significant differences between the groups $(p<0.05)$.

\begin{tabular}{lccccc}
\hline Group & Time & DSPP & DMP1 & MMP20 & PHEX \\
\hline \multirow{2}{*}{ PLDL } & $6^{\text {th }}$ week & $1.027 \pm 0.441$ & $10.153 \pm 0.318^{a, b, *}$ & $4.911 \pm 0.544^{a, *}$ & $0.119 \pm 0.009^{a, b, *}$ \\
& $12^{\text {th }}$ week & $1.526 \pm 0.127^{a}$ & $12.622 \pm 1.236^{a, b}$ & $1.359 \pm 0.413^{b}$ & $17.867 \pm 1.973^{a, b}$ \\
PDL & $6^{\text {th }}$ week & $0.004 \pm 0.001^{*}$ & $0.001 \pm 0^{c, *}$ & $0.120 \pm 0.049^{c, *}$ & $0^{c, *}$ \\
& $12^{\text {th }}$ week & $6.495 \pm 1.053^{c}$ & $8.430 \pm 1.335^{c}$ & $2.183 \pm 0.170^{c}$ & $11.201 \pm 1.210^{c}$ \\
HA/TCP & $6^{\text {th }}$ week & $0.014 \pm 0.009^{*}$ & $6.119 \pm 0.065^{*}$ & $4.649 \pm 0.081^{*}$ & $0.648 \pm 0.007^{*}$ \\
& $12^{\text {th }}$ week & $1.031 \pm 0.093$ & $360.417 \pm 7.170$ & $0.964 \pm 0.355$ & $3.756 \pm 0.265$ \\
\hline
\end{tabular}

DSPP: dentin sialo-phosphoprotein; DMP1: dentin matrix protein-1; MMP20: enamelysin/matrix metalloproteinase 20; PHEX: the phosphate-regulating gene with homologies to endopeptidases on the $X$ chromosome; ${ }^{a, b, c}$ Repeated measure ANOVA, Bonferroni. PLDL x PDL: $a$, PLDL x HA-TCP: b, PDL $\times$ HA-TCP: ${ }^{*}{ }^{*}$ t-test, $6^{\text {th }}$ week $\times 12^{\text {th }}$ week.
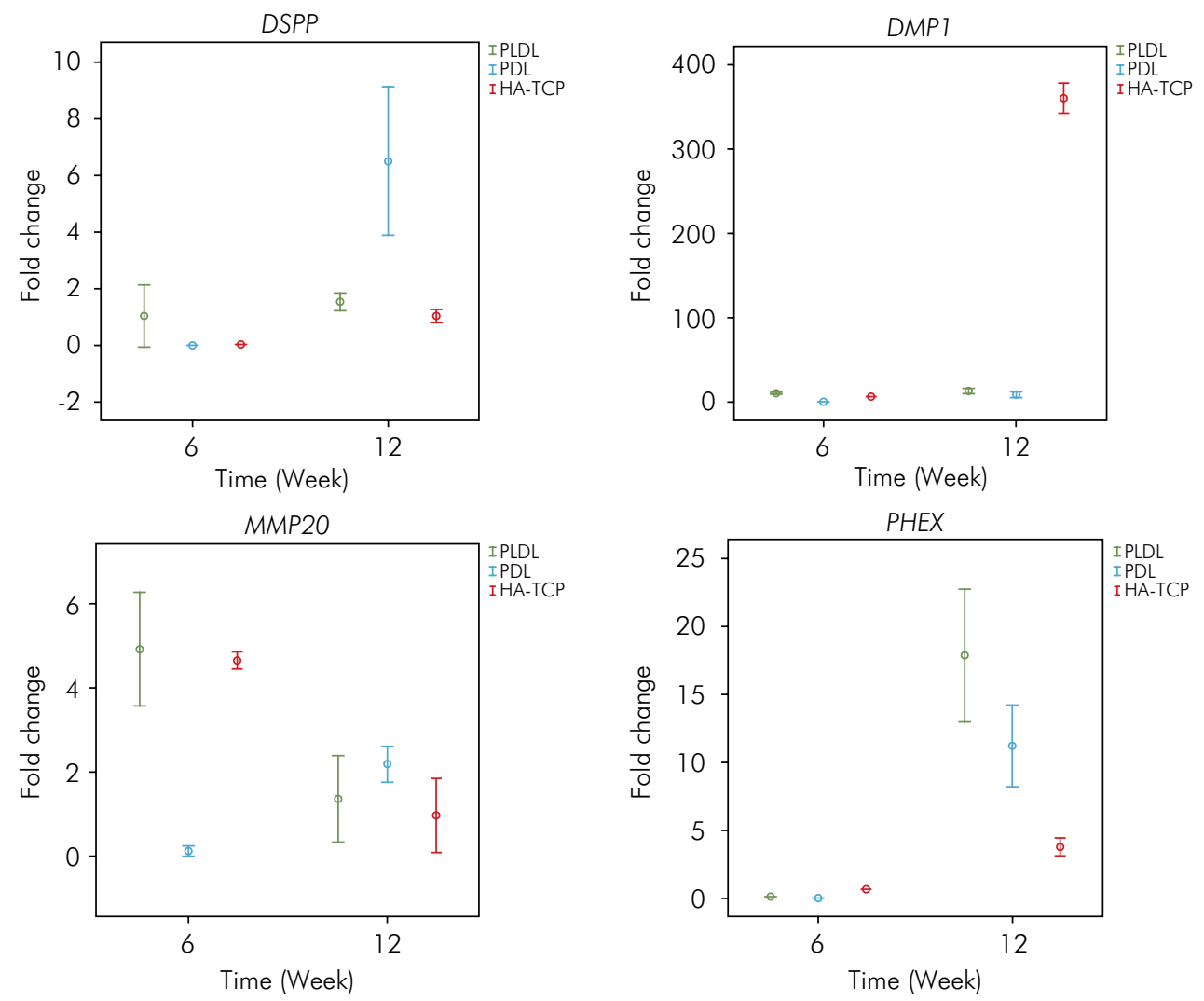

Figure. The fold change rates of DSPP, DMP1, MMP20 and PHEX in the experimental (+) groups compared to the control (-) groups for three scaffold materials, 6 and 12 weeks after transplantation. 
was determined in the PDL group at 12 weeks and was significantly different from those of the other groups ( $\mathrm{p}<0.05)$. The DSPP levels were observed to be similar in the PLDL and HA/TCP groups at 12 weeks $(p>0.05)$.

The highest $D M P 1$ expression was found in the PLDL group at 6 weeks $(\mathrm{p}<0.05)$. There was an increase in the expression of DMP1 in all groups consistent with the time period $(\mathrm{p}<0.05)$. The highest expression of DMP1 was shown in the HA/TCP group at 12 weeks $(\mathrm{p}<0.05)$.

The expression of MMP20 was similar in the PLDL and HA/TCP groups at 6 weeks $(p>0.05)$. Although the expression of $M M P 20$ was lowest in the PDL group at 6 weeks, it was the highest at 12 weeks $(p<0.05)$. No significant difference was observed between the PLDL and PDL groups for MMP20 expression at 12 weeks $(p>0.05)$.

The highest PHEX expression was observed in the HA/TCP group at 6 weeks $(\mathrm{p}<0.05)$. Although there was an increase in PHEX expression in all groups at 12 weeks, the highest expression was found in the PLDL group $(\mathrm{p}<0.05)$.

\section{Discussion}

Cells, morphogens and scaffolds are the key elements for cellular regeneration. It is important to understand the relationships among these elements to develop successful models for odontogenic regeneration. A model using DPSC, medium modification via the addition of rhBMP2 and three different scaffold materials (PLDL, PDL and HA-TCP) was tested in this study.

DPSC are postnatal somatic stem cells with high differentiation potential in response to environmental stimuli. ${ }^{14}$ The BMP family plays an active role in the initiation, morphogenesis and cytodifferentiation phases of tooth development. ${ }^{7}$ Bone morphogenetic protein 2 (BMP2) induces odontoblastic differentiation and dentin formation. ${ }^{8,17}$ The stimulation of odontoblastic differentiation in a cell culture before implantation has been reported to exert a positive influence on dentin formation. ${ }^{8}$ Accordingly, dexamethasone- and rhBMP2-supplemented odontogenic medium was used in the experimental $(+)$ groups of this study. This supplementation promoted the odontoblastic differentiation of DPSC and enhanced the expression of odontogenic/odontoblastic markers (Figure). The results verify the crucial role of growth factor (rhBMP2 in this study) in the odontogenic differentiation of DPSC. Similar results were obtained by using a combination of dexamethasone and bone morphogenetic protein 7 in a previous study. ${ }^{4}$ Medium modification via the addition of BMP2 has previously been reported to improve the in vivo performance of $\mathrm{HA} / \mathrm{TCP}^{18}$. Our results reveal the positive contribution of the above-described induction when using not only HA/TCP but also PLDL and PDL scaffolds.

Odontogenic regeneration starts with odontoblastic differentiation. $D S P P$, which is known as a marker for odontoblastic differentiation, is responsible for encoding dentin phosphoprotein (DPP) and dentin sialoprotein (DSP). Another extracellular matrix protein, $D M P 1$, has an active role during tooth development and odontoblastic differentiation. . $^{1920,21,22}$ The comparatively increased expressions of DSPP and DMP1 in the experimental (+) groups (Figure) are evidence of the differentiation of DPSC into functional odontoblasts. In addition, the highest level of the dentin transcripts (which is similar to tertiary dentin formation) at 12 weeks supports our findings (Table).

Enamelysin/MMP20 is responsible for the enamel matrix and is expressed during the secretory stage of dental enamel formation. ${ }^{23,24,25}$ PHEX is responsible for phosphate homeostasis. ${ }^{26}$ The increased expression of these transcripts are consistent with the time periods (Figure) and are related to the tissue organization in all three scaffold materials. Despite the absence of the fold change in PHEX expression in the PDL group at 6 weeks, the expression rate was consistent with those of the other scaffold materials at 12 weeks. The decrease of enamelysin/MMP20 level in the PLDL and HA-TCP groups at 12 weeks may be related to transient inactivity or to the structure of the scaffold materials. This finding also suggests the potential difficulty of enamel regeneration with these scaffold materials. However, PDL may be a more suitable scaffold material for enamel when considering the Enamelysin/MMP20 expression profile.

The complex structure of the tooth requires scaffold materials that have different tissue specifications 
when using the regenerative dentistry concept. Three different materials were tried as a scaffold in this study. Among these materials, HA/TCP is a recommended scaffold for hard tissue regeneration, and it has been tested before. ${ }^{6,14,15}$ This study is the first to report on two new polymers as scaffold materials. Our data suggest that PLDL and PDL copolymers may be appropriate scaffold materials for DPSC and odontogenic regeneration. The tested materials performed adequately in this research experiment, and each may have different advantages in future applications. It is difficult to evaluate one of them as being superior to another based on the RT-PCR results. The tested polymers seem to perform similarly to HA/TCP regarding the enamel-dentin transcript expressions. PLDL and PDL enhanced the odontogenic matrix formation within the applied experimental conditions. Further modifications will be necessary to improve polylactides as useful biomedical materials. ${ }^{27}$ Therefore, there is a need for further studies in this field.

New scaffold designs will increase the probability of the future implementation of the regenerative dentistry concept; however, the development of the appropriate materials for each clinical application is crucial. Biocompatibility and adequate matrix formation properties are considered essential in clinical situations. ${ }^{19}$ Biodegradation and the appropriate

\section{References}

1. Yildirim S, Fu SY, Kim K, Zhou H, Lee CH, Li A et al. Tooth regeneration: a revolution in stomatology and evolution in regenerative medicine. Int J Oral Sci. 2011;3(3):107-16. doi:10.4248/IJOS11042

2. La Noce M, Paino F, Spina A, Naddeo P, Montella R, Desiderio V et al. Dental pulp stem cells: state of the art and suggestions for a true translation of research into therapy. J Dent. 2014;42(7):761-8. doi:10.1016/j.jdent.2014.02.018

3. Yu J, Wang Y, Deng Z, Tang L, Li Y, Shi J et al. Odontogenic capability: bone marrow stromal stem cells versus dental pulp stem cells. Biol Cell. 2007;99(8):465-74. doi:10.1042/BC20070013

4. Wang J, Liu X, Jin X, Ma H, Hu J, Ni L et al. The odontogenic differentiation of human dental pulp stem cells on nanofibrous poly(L-lactic acid) scaffolds in vitro and in vivo. Acta Biomater. 2010;6(10):3856-63. doi: 10.1016/j.actbio.2010.04.009 structural configuration to meet clinical needs are reported to be the desired features. ${ }^{4}$ In this respect, the biocompatibility and biodegradability properties of PLDL and PDL arising from their copolymer structures are promising and may prove to be an advantage. New materials can also be designed by incorporating bioactive molecules into these copolymer structures. ${ }^{13}$ Biodegradable/biocompatible scaffolds loaded with growth factors will help optimize the biomaterial design. ${ }^{28}$ Thus, the site-specific pharmacological release of growth factors that have the desired kinetics and a crucial role in regeneration should be attempted by using PLDL and PDL scaffolds in further studies.

\section{Conclusion}

Within the limitations of this study, it can be concluded that medium modification by the addition of rhBMP2 expedites odontogenic differentiation. PLDL and PDL are promising scaffold candidates for odontogenic regeneration at least as HA-TCP, if they are applied with the DPSC induced for odontogenic differentiation.

\section{Acknowledgment}

This study was supported by Ege University's Scientific Research Foundation (2010-Dis-006). The authors sincerely thank Gul KAYRAK for her help in language editing.

5. Sonoyama W, Yamaza T, Gronthos S, Shi S. Multipotent stem cells in dental pulp. In: Freshney IA, Stacey GN, Auerbach JM., editors Culture of human stem cells. New Jersey: Wiley-Liss; 2007. p. 187-206

6. Zhang W, Walboomers XF, Osch GJ, van den Dolder J, Jansen JA. Hard tissue formation in a porous HA/TCP ceramic scaffold loaded with stromal cells derived from dental pulp and bone marrow. Tissue Eng Part A. 2008;14(2):285-94. doi:10.1089/tea.2007.0146

7. Nakashima M. Bone morphogenetic proteins in dentin regeneration for potential use in endodontic therapy. Cytokine Growth Factor Rev. 2005;16(3):369-76. doi:10.1016/j.cytogfr.2005.02.011

8. Iohara K, Nakashima M, Ito M, Ishikawa M, Nakasima A, Akamine A. Dentin regeneration by dental pulp stem cell therapy with recombinant human bone morphogenetic protein 2. J Dent Res. 2004;83(8):590-5. doi:10.1177/154405910408300802 
9. Jäger M, Fischer J, Dohrn W, Li X, Ayers DC, Czibere A et al. Dexamethasone modulates BMP-2 effects on mesenchymal stem cells in vitro. J Orthop Res. 2008;26(11):1440-8. doi:10.1002/jor.20565

10. Yang X, Walboomers XF, Beucken JJ, Bian Z, Fan M, Jansen JA. Hard tissue formation of STRO-1-selected rat dental pulp stem cells in vivo. Tissue Eng Part A. 2009;15(2):367-75. doi:10.1089/ten.tea.2008.0133

11. Bohl KS, Shon J, Rutherford B, Mooney DJ. Role of synthetic extracellular matrix in development of engineered dental pulp. J Biomater Sci Polym Ed. 1998;9(7):749-64. doi:10.1163/156856298X00127

12. Ma PX. Biomimetic materials for tissue engineering. Adv Drug Deliv Rev. 2008;60(2):184-98. doi:10.1016/j.addr.2007.08.041

13. Mauth C, Huwig A, Graf-Hausner U, Roulet J-F. Restorative applications for dental pulp theraphy. In: Ashammakhi N, Reis R, Chiellini E, editors. Topics in tissue engineering. Tampere: Expertissues; 2007. [cited 201604 12]. Vol. 3, p. 1-32. Available from: http:// www.oulu.fi/spareparts/ebook_topics_in_t_e_vol3/

14. Gronthos S, Brahim J, Li W, Fisher LW, Cherman $\mathrm{N}$, Boyde A et al. Stem cell properties of human dental pulp stem cells. J Dent Res. 2002;81(8):531-5. doi:10.1177/154405910208100806

15. Gronthos S, Mankani M, Brahim J, Robey PG, Shi S. Postnatal human dental pulp stem cells (DPSCs) in vitro and in vivo. Proc Natl Acad Sci USA. 2000;97(25):13625-30. doi:10.1073/pnas.240309797

16. Livak KJ, Schmittgen TD. Analysis of relative gene expression data using real-time quantitative PCR and the $2^{(-\Delta \Delta C(\mathrm{~T}))}$ method. Methods. 2001;25(4):402-8. doi:10.1006/meth.2001.1262

17. Nakashima M, Reddi AH. The application of bone morphogenetic proteins to dental tissue engineering. Nat Biotechnol. 2003;21(9):1025-32. doi:10.1038/nbt864

18. Atalayin C, Tezel H, Dagci T, Yavasoglu NU, Oktem G. Medium modification with bone morphogenetic protein 2 addition for odontogenic differentiation. Braz Oral Res. 2016;30(1):e20. doi:10.1590/1807-3107BOR-2016.vol30.0020

19. Cavalcanti BN, Zeitlin BD, Nör JE. A hydrogel scaffold that maintains viability and supports differentiation of dental pulp stem cells. Dent Mater. 2013;29(1):97-102. doi:10.1016/j.dental.2012.08.002
20. Sakai VT, Zhang Z, Dong Z, Neiva KG, Machado MA, Shi $S$ et al. SHED differentiate into functional odontoblasts and endothelium. J Dent Res. 2010;89(8):791-6. doi:10.1177/0022034510368647

21. D'Souza RN, Cavender A, Sunavala G, Alvarez J, Ohshima T, Kulkarni AB et al. Gene expression patterns of murine dentin matrix protein 1 (Dmp1) and dentin sialophosphoprotein (DSPP) suggest distinct developmental functions in vivo. J Bone Miner Res. 1997;12(12):2040-9. doi:10.1359/jbmr.1997.12.12.2040

22. MacDougall M, Simmons D, Luan X, Nydegger J, Feng J, $\mathrm{Gu}$ TT. Dentin phosphoprotein and dentin sialoprotein are cleavage products expressed from a single transcript coded by a gene on human chromosome 4 . Dentin phosphoprotein DNA sequence determination. J Biol Chem. 1997;272(2):835-42. doi:10.1074/jbc.272.2.835

23. Hu JC, Sun X, Zhang C, Liu S, Bartlett JD, Simmer JP. Enamelysin and kallikrein-4 mRNA expression in developing mouse molars. Eur J Oral Sci. 2002;110(4):307-15. doi:10.1034/j.1600-0722.2002.21301.x

24. Hu JC, Chun YH, Al Hazzazzi T, Simmer JP. Enamel formation and amelogenesis imperfecta. Cells Tissues Organs. 2007 Jul;186(1):78-85. doi:10.1159/000102683

25. Bègue-Kirn C, Krebsbach PH, Bartlett JD, Butler WT. Dentin sialoprotein, dentin phosphoprotein, enamelysin and ameloblastin: tooth-specific molecules that are distinctively expressed during murine dental differentiation. Eur J Oral Sci. 1998;106(5):963-70. doi:10.1046/j.0909-8836.1998.eos106510.x

26. Ruchon AF, Marcinkiewicz M, Siegfried G, Tenenhouse HS, DesGroseillers L, Crine P et al. Pex mRNA is localized in developing mouse osteoblasts and odontoblasts. J Histochem Cytochem. 1998;46(4):459-68. doi:10.1177/002215549804600405

27. Darensbourg DJ, Choi W, Karroonnirun O, Bhuvanesh $\mathrm{N}$. Ring-opening polymerization of cyclic monomers by complexes derived from biocompatible metals. Production of poly(lactide), poly(trimethylene carbonate), and their copolymers. Macromolecules. 2008;41(10):3493-502. doi:10.1021/ma800078t

28. Egri S, Eczacioğlu N. Sequential VEGF and BMP-2 releasing PLA-PEG-PLA scaffolds for bone tissue engineering: I. Design and in vitro tests. Artif Cells Nanomed Biotechnol. 2016 Feb 25. doi:10.3109/21691401.2016.1147454 